\title{
Stress, Fear of Failure and Fitness as Determinants of Decision Making among Nigerian Top Class Soccer Referees
}

\author{
By Jephtah Olaniyi Ogunsanya ${ }^{*}$ and Mutairu Akande Rasheed
}

\begin{abstract}
The two hypotheses were tested in this study: Stress, fear of failure and fitness will not relatively be significant determinants of decision making among Nigerian top class soccer referees; Stress, fear of failure and fitness will not compositely be significant determinants of decision making among Nigerian top class soccer referees. This study examined stress, fear of failure and fitness as determinants of decision making among Nigerian top class soccer referees. Multistage (Purposive, stratified, proportional and convenient) sampling techniques were used in selecting 101 respondents. The descriptive survey research design was adopted for the study while Four Instruments were used. They were Stress Scale (SS), Fear of failure Scale (FFS) and Fitness Scale (FS) and Decision Making Scale (DMS) with the following reliability values 0.71, 0.80, 0.69 and 0.77 through Cronbach's alpha respectively. The inferential statistics of multiple regression was used to test the hypotheses. The two null hypotheses tested at 0.05 level of significance were rejected which implied that Stress, fear of failure and fitness had relative and composite significance contribution for decision making among Nigerian top class soccer referees. It was however recommended that there is need to develop strategies to effectively cope with stressful situations for referees. Referees should be assisted in their ability to cope with these stressors which could be through any number of stress management techniques. Periodic workshops and seminars should be organized for all graded referees irrespective of their status on psychological traits that would enhance their performance.
\end{abstract}

Keywords: Decision Making, Fear of Failure, Fitness, Soccer Referees and Nigeria, Stress.

\section{Introduction}

Referees should have excellent vision ability in order to notice all actions on the court during a game. Referees should also have cognition skills to anticipate the actions of the persons involved in the game to know which actions to observe, and to make fast and adequate decision (Holdhaus 2011).

Although athletes and coaches have been the focus of thousands of studies in the field of sport psychology, sports officials in general and, perhaps, soccer referees in particular, have been notably neglected (Philippe et al. 2009). Topclass soccer referees operate within a complex, ever-changing environment that imposes considerable pressure on them, and a wide range of demands accompany their role within the soccer industry (Buraimo et al. 2010). Referees have to fulfill their role as match officials, i.e. coping with the social pressure associated with

*Principal Lecturer, Emmanuel Alayande College of Education Oyo, Nigeria.

${ }^{\dagger}$ Lecturer I, Emmanuel Alayande College of Education Oyo, Nigeria. 
professional soccer (Dawson and Dobson 2010). Soccer referees have a challenging job, due to the many aspects of a match that they must take into account, the speed and complexity of the decisions they must make, the repercussions their actions have, the number of people involved in the match, and often the hostile nature of spectators at the sport event. All this not only makes the job very complex, but also makes it easy to commit mistakes. As a consequence of the constant decision-making, the subjectivity of referees when assessing actions, and the mistakes they may make, they are often criticized for their decisions (Anderson and Pierce 2009).

Throughout the game, referees and assistant referees have to make correct decisions under time constraints, with the correctness of those decisions constantly evaluated. The referee must be competent in the application of all rules, be in the appropriate field position to see the players, and make fast and accurate decisions. In recent years, an increasing body of research has emerged examining the physiological demands and decision making requirements of referees (Weston 2015).

Moreover, as highlighted by MacMahon et al. (2007), the role of the referee is actually more complex than that of the athlete (or the coach), in that it requires a high degree of physical fitness as well as complex decisionmaking in the application of the rules of the game. A referee's decision may also be associated with his or her positioning during the soccer match. In order to minimize problems with visualization and positioning during a match, the Fédération Internationale de Football Association (FIFA 1982) established a diagonal system of control for referees. The diagonal system is designed to facilitate a good view of play and, therefore, good decision-making for both the referee and his/her assistant referees, who are meant to work together as a team. Referees are advised to move diagonally on the field, from corner to corner, and to avoid being ahead of the ball in order to get a better view of the game these acts require fitness on the part of the referees.

The term "stress" may be defined as "an ongoing process that involves individuals transacting with their environments, making appraisals of the situations they find themselves in, and endeavoring to cope with any issues that may arise" ( Fletcher and Scott 2010). Much anecdotal evidence suggests that officiating can indeed be a stressful profession (Voight 2009).

However, soccer referee often experience various forms of stress during a single contest, such as physical assault, making an error or dealing with verbal abuse. It has also been indicated in empirical studies that stress due to officiating could have an intensive effect upon the referee's mental health, performance, attention focus and drop-out determinations (Forbes and Livingston 2013, Kilani et al. 2013). The top sources of stress experienced by the soccer officials included wrong decisions, physical aggression, lack of physical fitness concerns, roleculture conflict, fear of failure conflict between officiating and family demands, making a controversial call and conflict between officiating and work demands (Voight 2009).

Researchers have also shown that referees' decisions can be influenced by fear and crowd factors Referees viewing videotaped potential fouls with fear 
and crowd noise call significantly fewer fouls for the away team than those presented with just the video; the referees presented with audio also more closely reflect the judgments of the actual match official (Nevill et al. 1999, 2002).

Previous studies investigated have shown decision making among sport officials before and during a game, especially in the game of soccer revealed the emotional and physical processes of referees. One may claim that emotions are disruptive and destructive forces that undermine optimal decision-making and that emotions affect the process of decision-making, for better and for worse (Lazarus 2000, Zhu and Thagard 2002). Indeed, Hoseini et al. (2011) claimed that judging soccer is a mental process that requires quick decisions and that, because of the importance of professional soccer games, the difficulty of officiating is increasing.

Although there have been some researches related to emotional issues in referees, such as their responses to stress (e.g. Anshel and Weinberg 1995, Dorsch and Paskevich 2007, Thatcher 2005) and use of coping strategies (e.g. Anshel and Weinberg 1999), little research has been focused on the determinants of anxiety level and decision-making among professional soccer referees. It is on this note that the researcher intends to ascertain stress, fear of failure and fitness as determinants of decision making among Nigerian top class soccer referees.

\section{General Objective of the Study}

The main objective of this study is to examine stress, fear of failure and fitness as determinants of decision making among Nigerian top class soccer referees.

\section{Specific Objectives of the Study}

The specific objectives of this study were:

1. To determine the relative contribution of stress, fear of failure and fitness as determinants of decision making among Nigerian top class soccer referees.

2. To determine the composite contribution of stress, fear of failure and fitness as determinants of decision making among Nigerian top class soccer referees.

\section{Research Questions}

1. Would stress, fear of failure and fitness relatively be determinants of decision making among Nigerian top class soccer referees.

2. Would stress, fear of failure and fitness compositely be determinants of decision making among Nigerian top class soccer referees. 


\section{Hypotheses}

The following hypotheses were tested in this study:

1. Stress, fear of failure and fitness will not relatively be significant determinants of decision making among Nigerian top class soccer referees.

2. Stress, fear of failure and fitness will not compositely be significant determinants of decision making among Nigerian top class soccer referees.

\section{Significance of the Study}

This study will examine stress, fear of failure and fitness variables that might determined decision making among Nigerian top class soccer referees as well promote data for referees in this regard.

The study would also provide assistance and encouragement to institutions and bodies in the development of program for soccer referees.

The findings will assist the organizers and soccer institutions to have a better understanding of their officials on the impact of stress, fear of failure and fitness on decision making among soccer referees.

It is also hoped that the findings may help the institutions and related bodies to develop a better plan that can guide and expose soccer referees to understand the profession clearly.

The finding of the study would provide insight for the soccer governing bodies on the need to create enabling environments for the referees towards any championship.

The findings of the study will further help the referees to identify those factors that would enhance their success when chosen soccer officiating as a career. Finally, the study would serve as a spring board for further research into the state of soccer officiating.

\section{Methodology}

The descriptive survey research design was adopted for this study. The population for the study consists of top class soccer referees in Nigeria. The sample size for the study was one hundred and one (101) respondents. The multi-stage sampling procedure was used in conducting the study. In the first stage, purposive sampling technique was used to select the Nigerian top class Soccer Referees. In the second stage stratified sampling technique was used to select top Soccer Referees according to the league officiated. In the third stage proportional sampling technique was also used to select $70 \%$ of the total Referees from each league officiated while convenient sampling technique, was used to select require top class Soccer referees in Nigeria. The research instrument was a self-developed questionnaire which contained four Instruments. They were Stress Scale (SS), Fear of failure Scale (FFS) and Fitness Scale (FS) 
and Decision Making Scale (DMS) with the following reliability values 0.71, 0.80, 0.69 and 0.77 through Cronbach's alpha respectively with the modified of three and four points scale of summative rating to show the extent of agreement or disagreement, was used to collect data for the study. In ensuring the reliability of the instrument, the corrected versions of the self-developed questionnaire was administered to 20 respondents that were drawn from the nonleague officiated Referees. The results of the data collected were subjected to Cronbach Alpha reliability test values reported above. The descriptive statistics of frequencies counts and percentage were used to describe section $\mathrm{A}$ of the questionnaire, which highlight the demographic characteristics of the respondents while inferential statistics of multiple regression was used to test the hypotheses at 0.05 alpha level.

Table 1. Population, Sampled, Age and Sex

\begin{tabular}{|c|c|c|c|c|c|}
\hline S/N & $\begin{array}{c}\text { League } \\
\text { officiated }\end{array}$ & $\begin{array}{c}\text { Number of } \\
\text { Referees }\end{array}$ & $\begin{array}{c}\text { Sampled } \\
\text { Referees (70\%) }\end{array}$ & \multicolumn{1}{|c|}{ Age } & Sex \\
\hline 1 & NPFL & 70 & 49 & $\begin{array}{l}21-30 \text { years }=33 \\
31-30 \text { years=16 }\end{array}$ & $\begin{array}{l}\text { Male=41 } \\
\text { Female=8 }\end{array}$ \\
\hline 2 & NNL & 74 & 52 & $\begin{array}{l}21-30 \text { years=41 } \\
31-40 y e a r s=11\end{array}$ & $\begin{array}{l}\text { Male=43 } \\
\text { Female=09 }\end{array}$ \\
\hline
\end{tabular}

Notes: Nigeria Professional Football League (NPFL)\&Nigeria National League (NNL).

\section{Results and Discussion of the Findings}

$\mathrm{H}_{01}$ : Stress, Fear of failure and Fitness will not relatively be significant determinants of decision making among Nigerian top class soccer referees.

Table 2. Relative Contribution of Stress, Fear of Failure and Fitness as Determinants of Decision Making Among Nigerian Top Class Soccer Referees

\begin{tabular}{|l|c|c|c|c|c|c|}
\hline $\begin{array}{l}\text { Independent } \\
\text { Variables }\end{array}$ & $\mathbf{B}$ & Standard error B & Beta $\boldsymbol{\beta}$ & $\mathbf{T}$ & Sig & Remark \\
\hline Stress & 0.130 & 0.407 & 0.325 & 2.776 & 0.005 & Sig \\
\hline $\begin{array}{l}\text { Fear of } \\
\text { failure }\end{array}$ & 0.349 & 0.244 & 0.184 & 1.432 & 0.001 & Sig \\
\hline Fitness & 0.211 & 0.233 & 0.112 & 1.246 & 0.000 & Sig \\
\hline
\end{tabular}

Table 2 showed the unstandardized and standardized regression weight of the ${ }^{B B}$, the standard error of Beta $(\beta \beta)$, the Beta $(\beta \beta)$, the value of $\mathrm{t}$ for the regression of independent variables of stress, fear of failure and fitness on dependent variable of decision making and significant $P$ value.

The table above revealed that the B-value of Stress, fear of failure and fitness were $(0.130),(0.349)$ and $(0.211)$ respectively. These showed the level of contribution of stress, fear of failure and fitness as determinants for decision making among Nigerian top class soccer referees. Their standardized regression weight Beta $(\beta)$ were stress $(0.325)$, fear of failure $(0.184)$ and fitness $(0.112)$ 
which showed relationship between stress, fear of failure and fitness and decision making among Nigerian top class soccer referees. Their t-values were Stress (2.776), fear of failure (1.432) and fitness (1.246) at significant levels of Stress (0.005), fear of failure (0.001) and fitness (0.000) respectively.

Table 1 showed that the null hypothesis was statistically significant. The null hypothesis was therefore rejected. Precisely, the result showed that Stress, fear of failure and fitness had significant effect for decision making among Nigerian top class soccer referees.

$\mathrm{H}_{02}$ : Stress, fear of failure and fitness will not compositely be significant determinants of decision making among Nigerian top class soccer referees.

Table 3. Shown Composite Contribution of the Stress, Fear of Failure and Fitness as Determinants of Decision Making Among Nigerian Top Class Soccer Referees

\begin{tabular}{|l|c|c|c|c|c|c|}
\hline Model & Sum of Squares & DF & Mean Square & F & Sig & Remark \\
\hline Regression & 1024.938 & 5 & 204.988 & 3.145 & .001 & \\
$\begin{array}{l}\text { Residual } \\
\text { Total }\end{array}$ & 6192.013 & 95 & 65.179 & & & Sig. \\
\hline
\end{tabular}

$\mathrm{R}=.377$

$\mathrm{R}^{2}=.042$

$\operatorname{Adj} R=.097$

It was shown in Table 3 above that there was composite contribution of the stress, fear of failure and fitness as determinants of decision making among Nigerian top class soccer referees.

It could be observed that the correlation was $(\mathrm{R}=0.377)$. The adjusted $\mathrm{R}$-square indicated that $42 \%$ of the variance accounted for stress, fear of failure and fitness as determinants for decision making among Nigerian top class soccer referees. Also, the table showed the effectiveness of the prediction with the F-ratio 3.145 and significant alpha (0.001).

Based on the above finding, the result showed significant composite contribution of stress, fear of failure and fitness as determinants for decision making among Nigerian top class soccer referees, therefore, the null hypothesis was rejected.

It could therefore, be said that stress, fear of failure and fitness when combined together would contribute to the determinants for decision making among Nigerian top class soccer referees.

\section{Discussion of the Findings}

According to Castagna et al. (2007), the physical requirements of top-level football referees have shown them to run similar distances as professional players. For example, referees in the English premier league ran $9.5 \mathrm{~km}$ and an 
International level referee was found to run $11.36 \mathrm{~km}$. He concluded that referees covered $47 \%$ of the distance at a jogging pace, $23 \%$ walking, $12 \%$ sprinting and $18 \%$ running backwards. Caballero et al. (2011) stated that referees play a crucial role in modern soccer and the importance of decision during match-play can be critical for the final score of the match. Abass et al. (2011) concluded that the Nigerian soccer referees are always seen to have good speed performance when officiating in the National Professional League competition.

The high match physical demand imposed on soccer referees (Weston et al. 2012) necessitates a good level of physical fitness to ensure referees can keep up with play at all times and obtain optimal positions when making key decisions. Therefore, physical training programmes informed by the science of match analysis would appear logical. While physical considerations will always be secondary to the ability to fulfill a technical role on the field of play, inadequate physical preparation could limit technical functioning during a match (MendezVillanueva and Buchheit 2013). With this in mind, training programmes with an emphasis on high-intensity running - the key physical performance indicator are beneficial for the fitness of soccer referees Weston et al. 2012).

Physiological and motor performance skills such as cardiovascular endurance, muscular endurance, and muscular strength, resting heart rate, blood pressure, speed, agility and mental skills such as visual perception, attention, concentration, composure and decision-making are all required by referees at any level of the game. The ability to cope with the pressures of refereeing had increased.

The responsibilities of soccer referees are to control players' behaviour and implement the rules of the game during competitive football. These place strenuous task on the referee's speed performances as well as bio-physiological functioning. The Nigerian Soccer Referees are always seen to have good speed performance when officiating in the National premier and Professional League competitions but were not seen at International levels, (Abass et al. 2011). Asagba (2004) established that officiating officials in soccer have some moments of robust runs and sudden stoppages, intermingled with uneven walks and shuttles in different directions. Abass (2005) supported that; aerobic ability cannot see a soccer referee through successfully in ball games because of these frequent changes of space and need for sudden sprints. In this direction, therefore, referees must maintain a constant training programmed from time to time as they mature with officiating age. Asagba (2004) contributed by saying that, a soccer referee is supposed to be within 10 to $15 \mathrm{~m}$ range from the ball at any time during play. Baumhakel et al. (2007) submitted that referees should have good physical condition as requirements during a match.

Muscular endurance is one of the specific requirements which has been defined and described in various ways by different authors. Hickson (1980) defined endurance (also called sufferance, stamina, resilience) as the ability of an organism to exert itself and remain active for a long period of time, as well as its ability to resist, withstand, recover from, and have immunity to trauma, wounds, or fatigue. In humans, it is usually used in aerobic or anaerobic exercise. He went further and stated that, the definition varies according to the type of 
exertion- minutes for high intensity anaerobic exercises, hours or days for low intensity aerobic exercise. He concluded that, training for endurance can have a negative impact on the ability to exert strength unless an individual also undertakes resistance training to counteract this effect.

\section{Conclusion and Recommendations}

Findings from this study showed that Stress, fear of failure and fitness had significant relative contribution for decision making among Nigerian top class soccer referees.

The findings also shown that stress, fear of failure and fitness when combined together would contribute to the determinants of decision making among Nigerian top class soccer referees.

Based on this conclusion, there is need to develop strategies to effectively cope with stressful situations for referees. Referees should be assisted in their ability to cope with these stressors which could be through any number of stress management techniques. Training of referees on special programs associated with fear of failure and decision making as well as to rehabilitate and train them to take the right decision at the right time without fear of molestation.

To ensure professional competence among referees, there should be establishment of standard referee training school for all referees where they would be tested and certified before their appointment for a match. Periodic workshops and seminars should be organized for all graded referees irrespective of their status on psychological traits that would enhance their performance.

\section{References}

Abass AO (2005) Correlational effects of plyometric training on leg muscle strength endurance and power characteristics of Nigeria University Undergraduates. International Journal of African-American Students 5(1): 80-86.

Abass AO, Moses MO, Alabi EF, Adedugbe BO, Falola KO, Abayomi AO (2011) Relationships between bio-physiological parameters and speed performance of Nigerian FIFA referees. Journal of Physical and Education and Sports Management 3(20): 60-65.

Asagba BO (2004) The need for sports officiating officials to be physically fit. West African Journal of Physical \& Health Education. 8(1): 90-99.

Anderson KJ, Pierce DA (2009) Officiating bias: the effect of foul differential on foul calls in NCAA basketball. Journal of Sports Sciences 27(7): 687-694.

Anshel MH, Weinberg RS (1995) Sources of acute stress in American and Australian basketball referees. Journal of Applied Sport Psychology 7(1): 11-22. Doi: 10.1080/ 10413209508406297.

Anshel MH, Weinberg RS (1999) Re-examining coping among basketball referees following Stressful events: Implications for coping interventions. Journal of Sport Behavior 22(2): 141-161. Doi: 10.1080/10413209508406297.

Baumhakel M, Kinderman M, Kindermann I, Bohm M (2007) Soccer world championship: A challenge for the cardiologist. European Heart Journal 28(2): 150-153. 
Buraimo B, Forrest D, Simmons R (2010) The twelfth man? Refereeing bias in English and German soccer. Journal of the Royal Statistical Society: Series A 173(2): 431449. Doi: 10.1111/j.1467-985X.2009.00604.x.

Caballero JAR, Ojeda EB, Garcia-Aranda JM, Mallo J, Werner H, Sarmiento S, Valdivielso MN (2011) Physiological profile of national-level Spanish soccer referees. International Sportmed Journal 12(2): 85-91.

Castagna C, Abt G, D'Ottavio S (2007) Physiological aspects of soccer refereeing performance and training. Sports Medicine 37(7): 625- 46.

Dawson P, Dobson S (2010) The influence of social pressure and nationality on individual decisions: Evidence from the behaviour of referees. Journal of Economic Psychology 31(2): 181-191. Doi: 10.1016/j.joep.2009.06.001.

Dorsch KD, Paskevich DM (2007) Stressful experiences among six certification levels of ice Hockey officials. Psychology of Sport and Exercise 8(4): 585-593. Doi: 10.1016/j.psychsport.2006.06.003.

Fletcher D, Scott M (2010) Psychological stress in sport coaches: A review of concepts, research, and practice. Journal of Sports Sciences 28(2): 127-137.

Forbes SL, Livingston LA (2013) Changing the call: Rethinking attrition and retention in the ice hockey officiating ranks. Sport in Society 16(3): 295-309.

Hickson RC (1980) Interference of strength development by simultaneously training for strength and endurance. European Journal of Applied Physiology and Occupational Physiology 45(2-3): 255-263

Holdhaus H (2011) Shuttle Run Test and Training Advice, Guidelines for Referee Education 2011. European Handball Federation, Vienna.

Hoseini SH, Aslankhani MA, Abdoli B, Mohammadi F (2011) The relationship between number of crowds with anxiety and the function of the soccer premier league referees. Procedia-Social and Behavioral Sciences 30(2011): 2374-2378.

Kilani OW, Altahayneh ZL, Oudat MA (2013) Sources of stress and intention to quit among sport officials in Jordan. European Journal of Social Sciences 38(3): 365-373.

Lazarus RS (2000) How emotions influence performance in competitive sports. The Sport Psychologist 14(3): 229-252. Available at: https://bit.ly/2BjhTDo.

MacMahon C, Helsen WF, Starkes JL, Weston M (2007) Decision-making skills and deliberate practice in elite association football referees. Journal of Sport Sciences 25(1): 65-78.

Mendez-Villanueva A, Buchheit M (2013) Football-specific fitness testing: adding value or confirming the evidence. Journal of Sports Science 31(13): 1503-1508.

Nevill AM, Holder RL (1999) Home advantage in sport - An overview of studies on the advantage of playing at home. Sports Medicine 28(4): 221-236.

Philippe FL, Vallerand RJ, Andriananrisoa J, Brunel P (2009) Passion in referees: Examining their affective and cognitive experiences in sport situations. Journal of Sport \& Exercise Psychology 31(1): 77-96.

Thatcher J (2005) Stress, challenge, and impression management among sports officials. Sport and Exercise Psychology Review 1(1): 26-35.

Voight M (2009) Sources of stress and coping strategies of US soccer officials. Stress and Health 25(1): 91-110.

Weston M, Castagna C, Impellizzeri FM, Bizzini M, Williams AM, Gregson W (2012) Science and medicine applied to soccer refereeing. Sports Medicine 42(7): 615-631.

Weston M (2015) Match performances of soccer referees: the role of sport science. Movement and Sports Sciences 87: 113-117.

Zhu J, Thagard P (2002) Emotion and action. Philosophical Psychology 15(1): 19-36. 
